\title{
ANDRAGOGIJA
}

Prof. Jelisaveta Šafranj, Ph.D.

UDC: $159.923 .3:[371.3:: 811.111$

Faculty of Technical Sciences

Marina Katić, MSc.

Faculty of Technical Sciences

$159.953 .5: 811.111$

doi: 10.19090/ps.2019.1.69-81

Prihvaćen: 19. 6. 2019.

Primljen: 5. 5. 2019.

ORIGINAL SCIENTIFIC ARTICLE

\section{THE RELATIONSHIP BETWEEN BIG FIVE PERSONALITY TRAITS AND WILLINGNESS TO COMMUNICATE}

\author{
Abstract
}

The relationship between personality traits and willingness to communicate (WTC) in English language teaching (ELT) was investigated in this study. The examinees included 303 university students at Faculty of Technical Sciences in Novi Sad. Data were gathered using the International Personality Item Pool (IPIP; Goldberg, 2001) and Willingness to Communicate (WTC) Scale (McCroskey, 1992). When talking to strangers $33.7 \%$ of the examinees obtained low scores on WTC, $49.5 \%$ had medium levels of WTC and $16.8 \%$ had high WTC. When talking to acquaintances $36.3 \%$ of the examinees reported low levels of WTC, $46.9 \%$ reported moderate levels and $16.8 \%$ reported high levels of WTC. Similar results were reported when talking to friends. In addition, coefficients revealed significant positive correlations between WTC in EFL and all Big Five dimensions. Interpretation of the coefficients suggest that there was a small correlation between WTC in EFL and Conscientiousness, Emotional stability and Agreeableness. Moderate to high correlations were between WTC in EFL and Extraversion and Intellect. It was concluded that the interaction of the Big Five Personality Traits may significantly contribute to the promotion and production of WTC in learning English as a second language.

Keywords: Big Five Personality Traits, Willingness to Communicate, English language learning, individual differences.

\section{Introduction}

Traditionally, teaching English was aimed at mastering language in terms of its structure. However, with the arrival of the age of information and communication 
technology communication purposes have become more important and shifted English language teaching towards this direction, raising the importance of teaching communication. In addition, this led to the redefinition of the goal of language learning as communication between individuals with different mother tongue and different cultural backgrounds (Dörnyei, 2006; 2009). When emphasizing the importance of authentic communication in second language (L2) learning and instruction, the willingness to communicate (WTC) concept has several advantages, such as high levels of exposure to authentic L2 communication and practice, and development of learner autonomy (Zarrinabadi, 2014). A number of researchers (Ghonsooly,Khajavy\&Asadpour, 2012; Pavičić-Takač\&Požega, 2011; Peng, 2011) attempted to explain the factors that can highly influence individual differences in the success of second language learning, in addition to WTC. Many affective variables were identified, e.g. personality, attitude, motivation, self-esteem, self-confidence, identified competence, and language anxiety that affect individual learning differences. Thus, personality differences were the differences that recently attracted much attention (Goldberg, 1992).

Over the course of last several decades, the complex concept of personality was understood in various ways. A number of psychologists believe that trait is the best unit for describing personality, and thus, personality is the organizational form of traits (Halsam, 2007:18). McCrae\&Costa (1992) argue that the structure of personality can be outlined based on a relatively small number of factors that provide the evidence of the existence of the trait.

\section{The Big Five Personality Traits}

The Big Five Personality Traits, also known as the Five Factor Model (FFM) has been adopted by a number of personality psychologists (Goldberg, 1992). This empirical model suggests five broad dimensions to describe the human personality. These five dimensions are specified as openness to experience, conscientiousness, extraversion, agreeableness, and neuroticism. Each suggested factor consists of various correlated and more precise primary characteristics such as:

Openness to experience (inventive/curious vs. consistent/cautious). High openness can be regarded as unpredictability or lack of focus while people with low openness are trying to find satisfaction through well known things and actions.

Conscientiousness (efficient/organized vs. easy-going/careless). High conscientiousness is frequently understood as obsession and stubbornness while low conscientiousness is connected with spontaneity and flexibility.

Extraversion (outgoing/energetic vs. solitary/reserved). High extraversion is often regarded as authoritarian and attention-seeking while low extraversion originates a reticent, reflective personality. 
Agreeableness (friendly/compassionate vs. challenging/detached). High agreeableness is often seen as naive or submissive while low agreeableness personalities are often competitive or demanding people.

Neuroticism (sensitive/nervous vs. secure/confident). It refers to the impulse control and degree of emotional stability. A high need for stability is regarded as steady and collected personality, and a low need for stability causes a spontaneous and excitable personality.

In spite of some disagreements that still exist regarding the concept of trait and the arguments in favour of situation-specific behaviour opposite to the concept of trait (Kenrick\&Funder, 1998), many researchers defend the trait concept, explaining that it provides consistent reaction to similar situations over time instead of consistent reactions across different situations (Gregersen\&MacIntyre, 2014).Thus, many scholars (Costa,McCrae\&Kay, 1995:124) define personality as a rather permanent style of thinking, feeling, and acting of a person, which highly affects the use of language. Additionally, personality has been referred to in literature on WTC as a rather relevant factor (Adelifar,Jafarzadeh,Abbasnejhad\&Hasani, 2016).

\section{Theoretical principles}

The emergence of communicative teaching approach in second language learning has increased the importance of raising communicative competence in second language learners. In addition, some scholars (Swain\&Lapkin, 2002) suggest that learning through interactive meaningful communication in a pragmatic setting facilitates language learning. Swain (2000) believes that language use and language learning are parallel processes, and that using language promotes its learning. Consequently, determining the factors that constrain or facilitate the learners' ability to use the language is of vital importance. Some researchers (Simic\&Tanaka, 2008) highlight communication as an important objective in itself - an essential factor for the authentic use of second language and a crucial element of its learning. The authentic use of language has resulted in the increase of the number of studies carried out in the field of WTC, which became an important construct in second language learning.

Even if all factors concerning the surrounding are the same, theories outlined in social sciences cannot be applied to each and every individual. In addition to general theories developed by researchers, there are individual differences (IDs) among people that also play an important role. Scholars define individual differences as traits or features that differentiate individuals from each other (Dörnyei, 2009). IDs are minor differences, or hindrance that postpone general guidelines to be defined in the field of human behaviour (Dörnyei, 2009).Researchers in the field of second language learning need to take into account a number of individual differences, which will enable them to understand the differences in learners' rate and degree of success in the learning process. 
The importance of assessing the influence of WTC on success in English language learning is clear when taking into account the number of factors affecting the willingness to communicate, such as lack of self-esteem, fear of speaking and the problem of extroversion and introversion (McCroskey\&Richmond, 2013).Assessing the level of willingness to communicate in second language requires identifying the way people respond in situations when they are expected to speak. In situations when faced with the necessity to speak in the second language, some individuals find it easy to speak, while others try to avoid the opportunity. WTC can be defined as a reflection of psychological readiness to use the second language when required. The level of WTC is assumed to be both an influential factor in learning second language and the ability to communicate in the given language. Increasing levels of WTC can lead to higher language learning success rates. With higher WTC levels, higher frequency and amount of communication can be expected (McCroskey\&Richmond, 2013). The success of learning second language seems to depend on opting for speaking or refusing it. Indecisiveness is also usual when people are faced with the opportunity to use foreign language - the person wishes both to welcome the opportunity when he has a chance to speak, and avoid it (MacIntyre\&MacKinnon, 2007). Consequently, successful learning situation can be created by identifying the factors that contribute to the individual's decision to opt for using the chance to speak the foreign language.

MacIntyre (2007) believes that it is possible to determine the individual factors (motivation, interpersonal attraction, anxiety, attitudes, etc.), as well as the socially dependent factors (language contact, ethno linguistic vitality, etc.) that can contribute to or hinder willingness to communicate. The moment the individual opts to speak in foreign language, these factors initiate interaction.

The WTC in studying English language learning has induced a heated debate among scholars (Clement,Baker\&MacIntyre, 2003; Hashimoto, 2002; MacIntyre, 2007; McCroskey\&Richmond, 2013).The influence of personality traits on the level of WTC is highlighted in a number of studies. Some of them (MacIntyre,Babin\&Clement, 1999) suggest that perceived language competence and communication apprehension are a function of personality traits of Emotional stability and Extroversion/ Introversion. Others found that Agreeableness relates to WTC, along with the fact that personality traits of Emotional stability, Intellect, Conscientiousness, and Extroversion relate to WTC through perceived language competence, communication apprehension, and motivation (MacIntyre\&Charos, 1996).

On the other hand, some researchers consider WTC as a personality trait, describing it as "variability in talking behaviour" (McCroskey\&Richmond, 1990:146) and advocating that students may exhibit similar WTC propensities in a range of situations despite of the fact that situational variables may influence their WTC. In order to explain the individual's WTC in second language, MacIntyre and his associates (1998) constructed a comprehensive model by integrating the social psychological, communicative and linguistic variables. Moreover, they define willingness to communicate 
as the probability of opting for communication when given the chance. Nonetheless, instead of perceiving it as a personality trait, they treat WTC in second language as a situational variable with enduring and transient influence. They further believe that in addition to reading, writing and listening, WTC also affects speaking.

Thus, examining the role of WTC in second language learning requires studying the real language use environment thoroughly. Components, which are more important in terms of WTC in second language learning, represent another subject of disagreement among scholars in this field. Based on their own model, MacIntyre and his associates (1998) suggest that the person's WTC in second language is affected by his personality. They believe that individual's reaction to the member of second language group can be foreseen based on specific personality types.

Given the lack of in-depth studies, this research represents an attempt to provide a more comprehensive analysis regarding the influence of Big Five Personality Traits in identifying the students' unique modalities in WTC in the foreign language.

\section{Problem definition}

Some studies (MacIntyre et al., 1999; MacIntyre\&Charos, 1996) found that the learners' personality and their WTC are closely related. Personality traits of Emotional stability and Extroversion/Introversion were related to WTC through perceived language competence and communication apprehension (MacIntyre,Burns\&Jessome, 2011). While personality traits of Emotional stability, Extroversion, Intellect, and Conscientiousness are associated to WTC through communication apprehension, language competence, and motivation, the personality trait of Agreeableness is directly related to WTC (MacIntyre\&Charos, 1996).

Based on contemporary language teaching and learning methods, it is important to increase the communicative competence in second language learners. Foreign language courses have become more authentic with communicative language teaching (CLT), containing meaningful tasks and real-world simulation. Delivering lectures in a traditional manner has been enriched with interactions between the teacher and students, as well as among students themselves. This points to the crucial role of students' willingness to speak in order to learn second language (Adelifar et al., 2016).

Consequently, this study examines the relationship between personality traits and WTC among EFL university students. Personality traits and WTC are interrelated since they demonstrate individual differences. To the authors' knowledge, there are only few studies on the relationship between personality traits and WTC in EFL along with their contribution to second language learning in Serbia and worldwide. In addition, factors like staying some time in English speaking country and the age of starting learning English as a foreign language were also investigated in relation to WTC in EFL. Based on the research goal, the following research questions are stated:

1. What are EFL learners' perceived levels of WTC in a second language? 
2.Is there a relationship between personality traits and WTC in EFL?

3. Is there any relationship between staying some time in English speaking country and WTC in EFL? in EFL?

4. Does the age of starting to learn English language affect the levels of WTC

On the basis of the above questions the following hypotheses are stated:

H1:"EFL learners' perceive high levels of WTC." EFL."

$\mathrm{H} 2$ : "There is a positive relationship between personality traits and WTC in

H3: "Staying some time in English speaking country increases levels of WTC in EFL."

H4: "Age to start learning English language affects the levels of WTC in EFL"

\section{Method}

\section{Sample}

Sample comprised of 303 students (56.4\% female) attending Faculty of Technical Sciences. Mean age of the sample 20.68 years $(S D=2.02)$.The students were learning English language for minimum 3 years, while 8 years was the maximum. They freely agreed to participate without any compensation and were all informed about the study objectives. Two questionnaires were filled out in the Serbian language during the English class which lasted 15 minutes.

It is a convenience sample since it includes students of various interests attending various English courses at the Faculty of Technical Sciences. The respondents, who were easy to reach, were selected from the departments of mechanical engineering, electrical engineering, traffic engineering, biomedical engineering, architecture, graphic engineering and design, industrial management, and civil engineering and geodesy in order to reduce the possibility of biased sampling and enable reliable conclusion about examinees.

Table 1:

The sample structure

\begin{tabular}{lrr}
\hline \multicolumn{1}{c}{ Department } & N & \% \\
\hline Mechanical engineering & 38 & 12.54 \\
\hline Electrical engineering & 36 & 11.88 \\
\hline Traffic engineering & 40 & 13.20 \\
\hline Biomedical engineering & 39 & 12.87 \\
\hline
\end{tabular}


Prof. J. Šafranj, Ph.D., M. Katić, MSc.: THE RELATIONSHIP BETWEEN BIG FIVE PERSONALITY ...

\begin{tabular}{lll}
\hline Architecture & 37 & 12.21 \\
\hline Graphic engineering and design & 36 & 11.88 \\
\hline Industrial management & 38 & 12.54 \\
\hline Civil engineering and geodesy & 39 & 12.87 \\
\hline
\end{tabular}

\section{Instruments}

Data were gathered using the International Personality Item Pool (IPIP; Goldberg, 2001) and Willingness to Communicate (WTC) Scale (McCroskey, 1992).

Goldberg's Big Five Personality Traits from International Personality Item Pool (IPIP; Goldberg, 2001). Big five personality traits were assessed using Goldberg's items from public domain which are translated into the Serbian language. Each trait was assessed using 10 items followed by 5-point Likert scale ( 1 - totally disagree, 5 totally agree). Reliability of each scale was as it follows: Emotional stability $(\alpha=.85)$, Extraversion $(\alpha=.80)$, Intellect $(\alpha=.75)$, Agreeableness $(\alpha=.79)$, Conscientiousness $(\alpha=.76)$. All reliabilities were good or acceptable.

The willingness to communicate (WTC) scale (McCroskey, 1992) is a 20-item probability estimate scale from 0 (never) to 100 (always). It was translated into Serbian language and used to assess the students' WTC. The students indicated the percentage of time they would choose to communicate in each situation. The scale was designed as a direct measure of the respondent's predisposition toward approaching or avoiding the initiation of communication. WTC scale had high reliability $(\alpha=.87)$.

\section{Results}

Descriptive results indicate that most participants have average levels of WTC in EFL (48.2\%), but that there is also a relatively high number of participants with low WTC in EFL(37.0\%). There is somewhat lower percentage (14.9\%) of those that reported high WTC in EFL. When talking to strangers 33.7\% participants obtained low scores on WTC, $49.5 \%$ have medium levels of WTC and $16.8 \%$ have high WTC in case of communicating with strangers. On dimension of WTC with acquaintances $36.3 \%$ reported low levels, $46.9 \%$ reported moderate levels and $16.8 \%$ reported high levels. Similar levels of WTC were reported for friends dimension too. $32.7 \%$ had low levels, $52.5 \%$ had moderate levels and $14.9 \%$ had high levels of WTC with friends.

Pearson correlation coefficients between study variables are presented in table 2. Coefficients revealed significant positive correlations between WTC in EFL and all BIG 5 dimensions. Interpretation of the coefficients according to Cohen's guidelines (1988) suggest that there was a small positive correlation between WTC in EFL and Conscientiousness, Emotional stability and Agreeableness. Moderate positive correlations were between WTC in EFL and Extraversion and Intellect. 
Table 2

Pearson correlation coefficients between Big Five personality traits and L2 WTC

\begin{tabular}{lcccccc}
\hline & 1 & 2 & 3 & 4 & 5 & 6 \\
\hline 1. WTC & 1 & & & & & \\
2. Extraversion & $.43^{*}$ & 1 & & & & \\
3. Agreeableness & $.25^{*}$ & $.31^{*}$ & 1 & & & \\
4. Conscientiousness & $.17^{*}$ & $.18^{*}$ & $.40^{*}$ & 1 & & \\
5. Emotional stability & $.24^{*}$ & $.19^{*}$ & -.02 & $.19^{*}$ & 1 & \\
6. Intellect & $.30^{*}$ & $.25^{*}$ & $.26^{*}$ & $.25^{*}$ & .10 & 1 \\
\hline
\end{tabular}

Note. WTC - willingness to communicate.* $-\mathrm{p}<.01$.

In order to interpret relations between personality traits and WTC in a more systematic manner regression analysis was conducted with personality traits as predictors and WTC as criterion. Analysis was significant, F $(5,297)=21.48, p<.000$, which indicated that there was a significant influence of personality on WTC. Predictors explained $26 \%\left(\mathrm{R}^{2}=.26\right)$ of the criterion variance, and this is a moderate to large effect size according to Cohen (1988). Significance of t-tests for individual predictors (table 2) indicates that Extraversion, Agreeableness, Emotional Stability and Intellect have significant positive relations with WTC which points out that higher scores on these dimensions are associated with higher scores on WTC.

Table 3

Relative predictive power of personality dimensions for WTC

\begin{tabular}{lccc}
\hline Predictor & $\beta$ & $\mathrm{t}$ & $\mathrm{p}$ \\
\hline Extraversion & .324 & 5.960 & .000 \\
Agreeableness & .116 & 2.002 & .046 \\
Conscientiousness & -.007 & -.117 & .907 \\
Emotional stability & .166 & 3.178 & .002 \\
Intellect & .179 & 3.366 & .001 \\
\hline
\end{tabular}

In order to assess whether there were any significant differences between students that spent time in English speaking countries on personality traits and WTC series of independent $t$ tests were applied. Only significant $t$ test was for differences on Extraversion, $\mathrm{t}(301)=2.097, \mathrm{p}=.037$. Those that spent time in foreign country $(\mathrm{M}=$ $34.84, S D=7.59$ ) had higher scores on Extraversion than those that did not spend time in foreign country $(M=32.69, S D=7.12)$. 
It is interesting to note is that there were no significant differences between these two groups on L2 WTC measure. In order to further examine potential differences in WTC in EFL participants who spent time in foreign country were additionally separated in two groups: those that spent less than a month in foreign country, and those that spent more than a month. ANOVA indicated that there were no significant differences, $\mathrm{F}(2,300)=1.14, \mathrm{p}>.05$, in WTC in EFL between those that did not spend time in foreign country and those that did for less than a month and those that spent more.

ANOVA indicated that there were no significant differences on WTC, F $(2,300)$ $=.61, \mathrm{p}>.05$, between participants that started learning English before they were 11, those that started learning English at age $11-13$, and those that started later.

On the basis of the obtained results the following can be concluded:

H1: "EFL learners' perceive high levels of WTC." is rejected.

$\mathrm{H} 2$ : "There is a positive relationship between personality traits and WTC in EFL." is partially confirmed.

H3: "Staying some time in English speaking country increases levels of WTC in EFL." is rejected.

H4: "Age to start learning English language affects the levels of WTC in EFL" is rejected.

\section{Discussion}

Most of the examinees in this study show average levels of WTC in EFL (48.2\%), but there is also a significant number of students with low WTC in EFL $(37.0 \%)$. There is somewhat lower percentage $(14.9 \%)$ of those that reported high WTC in EFL. When talking to strangers $33.7 \%$ examinees obtained low scores on WTC, $49.5 \%$ have medium levels of WTC and $16.8 \%$ have high WTC in the case of communicating with strangers. On dimension of WTC with acquaintances $36.3 \%$ participants reported low levels, $46.9 \%$ reported moderate levels and $16.8 \%$ reported high levels. Similar levels of WTC were found for friends dimension $-32.7 \%$ had low levels, $52.5 \%$ had moderate levels and $14.9 \%$ had high levels of WTC with friends. The obtained results are partially consistent with the findings of the study $(\mathrm{Oz}, 2014)$ which indicated a satisfactory level of WTC of students majoring in EFL. These results are not in line with the other study(Pavičić-Takač\&Požega, 2011) whose examinees prefer to communicate with strangers in comparison with their friends and acquaintances. This finding implies that students are hesitant in one-to-one communication with their teachers, friends and people close to them.

The findings of our study revealed significant positive correlations between WTC in EFL and all Big Five dimensions. The results suggest that there is a small correlation between WTC in EFL and Conscientiousness, Emotional stability and Agreeableness, but moderate to high correlations were between WTC in EFL and Extraversion and Intellect. These findings are not in line with the results of previo- 
us study (Adelifar et al., 2016) which indicated that Agreeableness had a direct and negative correlation with WTC in EFL. Furthermore, Extroversion had no relationship with students' WTC. In addition, it was found a direct and negative relationship between Conscientiousness and WTC in EFL which was explained with the fact that consciousness is accompanied with desire to progress, self-discipline, loyalty, honesty, and caution, which means that these individuals are responsible and strive towards success and accomplishments. In addition, the same study indicated that Neuroticism had a direct and positive relationship to WTC in EFL which is in line with our findings. People with low Emotional stability respond emotionally and they are more willing to be involved in relationships.

The results of another study $(\mathrm{Oz}, 2014)$ are in line with ours and report that Extraversion and Intellect were the strongest predictors of WTC in EFL, indicating that students who are curious, sociable, creative, person-oriented, talkative, and friendly are more likely to communicate in foreign language. Similarly, individuals who are trusting, good-natured, straightforward and helpful also show a stronger inclination toward WTC in EFL. These findings are contrary to the previous study (Adelifar et. al., 2016) which noted that Intellect and Extraversion had no relationship with students' WTC.

When examining differences between students that spent some time in English speaking countries on personality traits and WTC the only difference was in Extraversion. Those that spent time in foreign country had higher scores on Extraversion than those that did not spend time in English speaking country. It is interesting to note is that there were no significant differences between these two groups on L2 WTC measure. Additionally, it was found that there were no significant differences, in WTC in EFL between students that did not spend time in English speaking country and those that did for less than a month and those that spent more time in English speaking society.

There were no significant differences on WTC in EFL between participants that started learning English before they were 11, those that started learning English at age $11-13$, and those that started later.

\section{Conclusion}

The findings of this research confirmed the results of previous studies emphasizing that in the field of psychology of individual differences (contemporary personality psychology) a person can be described with five major characteristics or basic dimensions. Each of these basic dimensions includes a series of specific personality traits and tendencies towards certain patterns of behaviour. The findings of the research on personality traits, as well as their inclusion in other theoretical constructs (cognitive style ...) support the fact of the previous methodological weaknesses, that is, the fact of idiosyncraticy, elusiveness as the most distinctive feature of the human nature, which is also manifested here clearly. With the current methodological powers 
it is hoped that one day we shall be closer to it, get to know it better in order to serve it better. The present findings are in favour of the conclusion that students should be grouped according to their individualities or individual personalities, with more or less expressed characteristics of different personality traits, and different learning materials and contents should be applied in teaching and learning activity. Thus, the tendency of grouping individuals according to their personality traits can be realized, and on this basis personalization of education should be accomplished. This implies that the teacher should offer more access to learning, and thus, didactic apparatus implies a wider repertoire of strategies that attempts to encourage students to take adequate, thus, effective approaches to their own learning. Some students are more willing to speak in foreign language while the others are more shy or reserved. Consequently, learning strategies, techniques, and approaches should be adopted in teaching procedure to tackle learners' personality traits and individual differences.

When considering the findings of this research, some future study should examine the issue of WTC in EFL using other variables that are interrelated with personality traits and are probable to affect it. Application of mixed-method research may provide more detailed findings as well.

In addition, qualitative aspect of the relationship between personality traits and willingness to communicate may be investigated in future. The results will be interesting and certainly provide significant insights.

\section{References}

Adelifar, M., Jafarzadeh, Z., Abbasnejhad, G., \& Hasani, A.S. (2016).The relationship between personality traits and WTC in EFL context, Journal of Studies in Social Sciences and Humanities, 2(2), 45-54.

Clement, R., Baker, S. C., \& MacIntyre, P. D. (2003). Willingness to communicate in a second language: The effects of context, norms, and vitality. Journal of Language and Social Psychology, 22, 190-209.

Cohen, J. (1988). Statistical power analysis for the behavioral sciences (2nd ed.).Hillsdale, NJ: Lawrence Earlbaum Associates

Costa P., McCrae, R., \& Kay, G. (1995). Person, places, and personality: Career assessment using the revised NEO personality inventory. Journal of Career Assessment, 3, 123-139.

Dörnyei, Z. (2009). The psychology of second language acquisition. Oxford Applied Linguistics. OUP Oxford.

Dörnyei, Z. (2006). Individual differences in second language acquisition. AILA Review, 19, 42-68.http://doi.org/b8s5fb

Ghonsooly, B., Khajavy, G. H., \& Asadpour, S. F. (2012). Willingness to communicate in Englishamong Iranian non-English major university students. Journal of Language and Social Psychology, 31, 197-211. http://doi.org/t9z 
Goldberg, L. R. (1992). The development of markers for the Big-Five factor structure. Psychological Assessment, 4, 26-42. http://doi.org/cd8

Goldberg, L. R. (2001). International Personality Item Pool. Retrieved from http://bit. ly/1 AfXuFc

Gregersen, T., \& MacIntyre, P. D. (2014). Capitalizing on individual differences: From premise topractice. Bristol, UK: Multilingual Matters.

Haslam N. (2007). The latent structure of mental disorders: A taxometric update on the categorical vs dimensional debate. Current Psychiatry Reviews: 3:172-177.

Hashimoto, Y. (2002). Motivation and willingness to communicate as predictors of reported L2 use: The Japanese ESL context. Second Language Studies, 20 (2), 2970.

Kenrick, D.T., \& Funder, D.C. (1998). Profiting from controversy: Lessons from the person-situation debate. American Psychologist, 43, 23-34.

MacIntyre, P.D., (2007). Willingness to communicate in the second language: Understanding the decision to speak as a volitional process. Modern language journal 91. 564- 576.

MacIntyre, P., \& Charos, C. (1996). Personality, attitudes, and affect as predictors of second language communication. Journal of Language and Social Psychology, $15,3-26$.

MacIntyre, P., Clement, R., Dornyei, Z. \& Noels, K. (1998). Conceptualizing willingness to communicate in a L2: A situational model of L2 confidence and affiliation. The Modern Language Journal, 82, 545-562.

MacIntyre, P. D., Babin, P. A., \& Clément, R. (1999). Willingness to communicate: Antecedents and consequences. Communication Quarterly, 47, 215-229.

MacIntyre, P. D., Burns, C., \& Jessome, A. (2011). Ambivalence about communicating in a second language: A qualitative study of French immersion students' willingness to communicate. The Modern Language Journal, 95, 81-96. http:// doi.org/ckhp25

MacIntyre, P. D. \& MacKinnon, S. P. (2007). Embracing affective ambivalence: A research agenda for understanding the interdependent processes of language anxiety and motivation. Presented at City University of Hong Kong, June, 2007.

McCrae, R. R. and Costa, P. T. Jr. (1992). 'Discriminant validity of NEO-PI-R facets', Educational and Psychological Measurement, 52: 229 237.

McCroskey, J. C., \& Richmond, V. P. (1990). Willingness to communicate: A cognitive view. In M. Booth-Butterfield (Ed.), Communication, cognition, and anxiety (pp. 19-37). Newbury Park, CA: Sage. (a)

McCroskey, J.C. (1992). Reliability and Validity of the Willingness to Communicate Scale. Communication Quarterly, 40, 16-25.

McCroskey, J. C., \& Richmond, V. P. (2013). Willingness to communicate (WTC). Measurement instrument database for the social science. Retrieved from http:// bit.ly/1rZgalB 
Oz, H. (2014). Big Five Personality Traits and Willingness to Communicate among Foreign Language Learners in Turkey, Social behavior and personality, 42(9): 1473-1482.

Pavičić Takač, V., \& Požega, D. (2011). Personality traits, willingness to communicate and oral proficiency in English as a foreign language. In L. Pon, V. Karabaliş, \& S. Cimer (Eds.), Applied linguistics today: Research and perspectives (pp. 67-82). Berlin, Germany: Lang.

Peng, J.-E. (2011). Towards an ecological understanding of willingness to communicate in EFL classrooms in China. System, 40, 203-213. http://doi.org/t96

Simic, M. and Tanaka, T. (2008). Language Context in the Willingness to Communicate Research Works: A Review. 71-88.

ousar.lib.okayama-u.ac.jp/file/14186/20090106041457/26_71.pdf

Swain, M. (2000). The output hypothesis and beyond: Mediating acquisition through collaborative dialogue. In J. P. Lantolf (Ed.), Socio cultural theory and second language learning (pp. 97- 114). Oxford: Oxford University Press.

Swain, M., \& Lapkin, S. (2002). Talking it through: two French immersion learners' response to reformulation. International Journal of Educational Research, 37, 285-304.

Zarrinabadi, N. (2014). Communicating in a second language: Investigating the effect of teacher onlearners' willingness to communicate. System, 42, 288-295. http:// doi.org/t97 